\title{
Qualitative evaluation of wastewater treatment plant performance by neural network model optimized by genetic algorithm
}

\author{
Sara Dadar ${ }^{1}$, Atena Pezeshki ${ }^{1}$, Bojan Đurin ${ }^{2, *}$, Dragana Dogančić ${ }^{3}$ \\ 1 Department of Water Science and Engineering, Faculty of Agriculture, Ferdowsi University of Mashhad, \\ Mashhad, Iran; sara.dadar@mail.um.ac.ir, atena.pezeshki@mail.um.ac.ir \\ 2 University North, Department of Civil Engineering, Varaždin, Croatia; bojan.durin@unin.hr \\ 3 University of Zagreb, Faculty of Geotehnical Engineering, Varaždin, Croatia; \\ dragana.dogancic@gfv.unizg.hr \\ * Correspondence: bdjurin@unin.hr; Tel.: +385-98-974-9716
}

\begin{abstract}
The adverse effects of improper disposal of collected and treated wastewater have become inevitable. In order to achieve the desired environmental standards, in addition to the construction of a wastewater treatment plant, there is also a need to evaluate the continuous performance of treatment systems. In Iran, treated wastewater is mostly used in agriculture. Therefore, the use of wastewater with poor quality characteristics can endanger health. In this study, the efficiency of the neural network model in order to predict the performance of the Parkandabad waste water treatment plant in Mashhad, with a semi-mechanical treatment system, was investigated. The first step in predicting the performance of the treatment plant was identification of factors affecting the Total Biochemical Oxygen Demand (TBOD) parameter which is one of the quality indicators of the effluent. In the next step, the neural network model optimized with a genetic algorithm, and effective features as network inputs was used for the predictions of the performance of the treatment plant. Based on the results obtained from the model, the parameters that affect the prediction of TBOD concentration the mostwere singled out and they are flow rate, organic matter load, dissolved oxygen concentration, temperature, and some active aerators. Paper will consider replacing the semi-mechanical treatment system with the activated sludge process.
\end{abstract}

Keywords: waste water; neural network; treatment plant; genetic algorithm; TBOD

\section{Introduction}

Today, population growth and industrial development have led to increased water consumption and, as a result, higher wastewater production and environmental pollution [1,2]. Improper disposal of urban and industrial wastewater causes adverse environmental effects. The implementation of wastewater projects in urban and rural areas is considered necessary and fundamental for environment preservation efforts [3]. The most important objectives during construction of wastewater treatment systems include different aspects, like maintaining public health, environmental protection, prevention of pollution of water resources, and reuse of treated wastewater [4]. The quality of effluent from the treatment plant is important both in terms of its uses in sectors such as agriculture and industry, and its final disposal site [5]. The quality primarily depends on important factors like the principles and parameters used during design of the plant itself, accuracy in the design, and how it is used. Therefore, accurate design and proper management of wastewater treatment plants are among the most important factors in the water and wastewater sector. Currently, the operation of many wastewater treatment plants in our country is facing problems due to various factors, such as, improper design, quantitative and qualitative changes in wastewater, process conditions, fluctuations in weather conditions during seasons, etc. Therefore, 
the use of methods that can predict the performance and efficiency of wastewater treatment plants and help to overcome forementioned problems is of particular importance. Based on these predictions, short-term and long-term management solutions can be provided, and the operators can take the necessary measures before the problems occur and in that way exercise proper control of the operations. One of the most widely used forecasting methods in the field of water and wastewater treatment is the artificial neural network method [6].

It is important to emphasize that the establishment of wastewater treatment plants alone does not address all environmental concerns, but the performance of treatment plants must be constantly monitored to achieve the desired environmental standards [7]. Wastewater treatment involves a set of complex physical, chemical, and biological processes whose dynamics are nonlinear and sometimes variable with time and can directly interfere with the operation of the treatment plant [8]. Among the common parameters used to evaluate the performance of wastewater treatment plants are the amount of oxygen required for biochemical processes (BOD), the amount of oxygen required for chemical processes (COD), the concentrations of suspended and soluble solids, and the $\mathrm{pH}$ of the effluent from this treatment plant [9]. Use of water from wastewater treatment plants can in some cases help solve the water shortage crisis in sectors such as agriculture and industry, but only if the amount of effluent pollutants complies with the standards [10].

In 2004, Oliveira Esquerre et al. used a neural network to obtain a satisfactory prediction of the BOD effluent from a wastewater treatment plant in Brazil. In this study, researchers first tried to predict the BOD parameter at the inlet and outlet of the treatment plant using linear regression models. They did not consider the use of linear regression to model the aeration lagoon treatment system in an industrial treatment plant suitable for the output parameters. Therefore, the use of regression models for aeration lagoons was not recommended. The researchers then applied interesting neural network models to the paper industry wastewater treatment system in Brazil, which had an aerated lagoon, and evaluated the neural network model for aerated lagoon system and similar systems [11]. Cao et al. [12] used an artificial neural network to predict the effect of changes in the parameters of an anaerobic B-2 system on its performance and used a parallel multi-population genetic algorithm to optimize the weights of the artificial neural network. The results of these researchers showed that the combination of these methods can provide a good tool for predicting changes in the performance of an anaerobic system. The researchers also concluded that due to the adaptations of these tools to different environmental conditions, they can be extended to other treatment systems. Abu Qdais et al. [13], used an artificial neural network and genetic algorithm as a tool to simulate and optimize the biogas production process in the digester of the Russaifah biogas plant in Jordan.

Fang et al. [14] developed a comprehensive dynamic model (including a mechanical model, a neural network model, and a genetic algorithm) to simulate the performance of a municipal wastewater treatment plant with significant fluctuations in inlet flow, and the neural network weights were optimized by genetic algorithm. Gueguim Kana et al. [15] modelled and optimized biogas produced from wastewater, including sawdust, cow dung, banana foliage, rice bran, and paper, using a neural network using a genetic algorithm. The results of this study show the effectiveness of the neural network model-genetic algorithm of nonlinear system behaviour and optimization of biogas production (15). Pieulac et al. (2013) developed a neural network optimization method and genetic algorithm and applied it to real electro-coagulation process. Validation of optimization results using experimental data showed an error of less than $11 \%$ (16).

This research has been used to develop and evaluate the efficiency of the neural network model and genetic algorithm in evaluating the performance of a large and important treatment plant in Mashhad and estimating the quality factors of its effluent.

\section{Materials and methods}

One of the most important municipal wastewater treatment plants in Mashhad is Perkandabad wastewater treatment plant No.1 (Figure 1), which is located on the southern bank of the seasonal river. The nominal capacity of this treatment plant is 15200 cubic meters per day and the 
population covered by it is equal to 100000 residents. The treatment process used in this treatment plant is an aerated lagoon with complete mixing, and the raw wastewater is treated by passing through the waste collection unit, aeration lagoons, sedimentation ponds, execution pond, and disinfection unit. Due to the discharge of effluent from the Perkandabad No.1 treatment plant into the river at certain times of the year, the design of this treatment plant is based on surface water discharge.

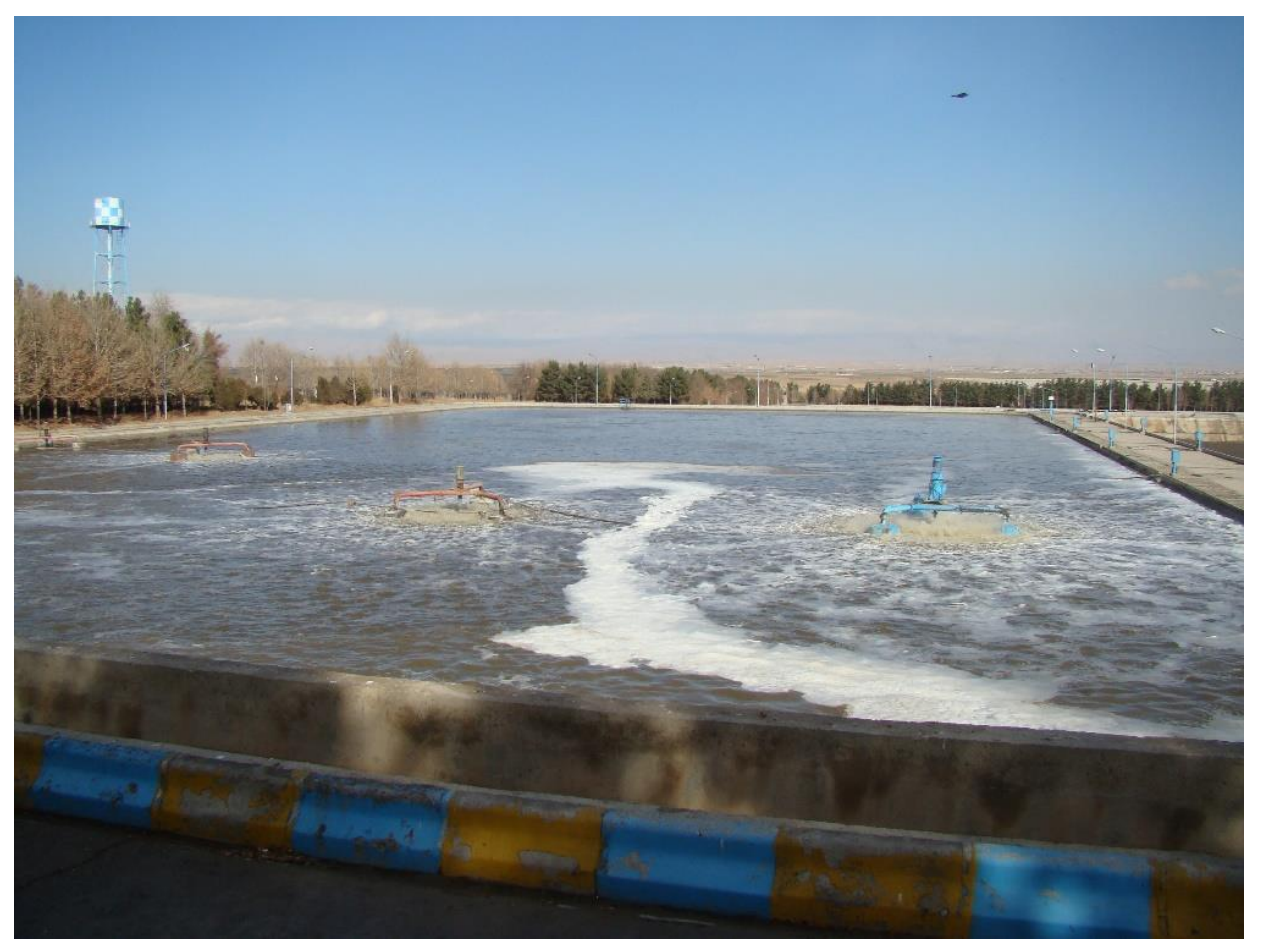

Figure 1. Perkandabad wastewater treatment plant.

The parameters examined for wastewater quality assessment were $\mathrm{BOD}_{5}$ (Biochemical Oxygen Demand in 5 days), COD (Chemical Oxygen Demand), TSS (Total Suspended Solids), and pH. Meteorological data was also used, including average daily air temperature, sunshine duration, and daily rainfall.

To start modelling of the neural network, first, the data was randomly divided for testing. The input and output data and the model architecture are shown in Figure 2.

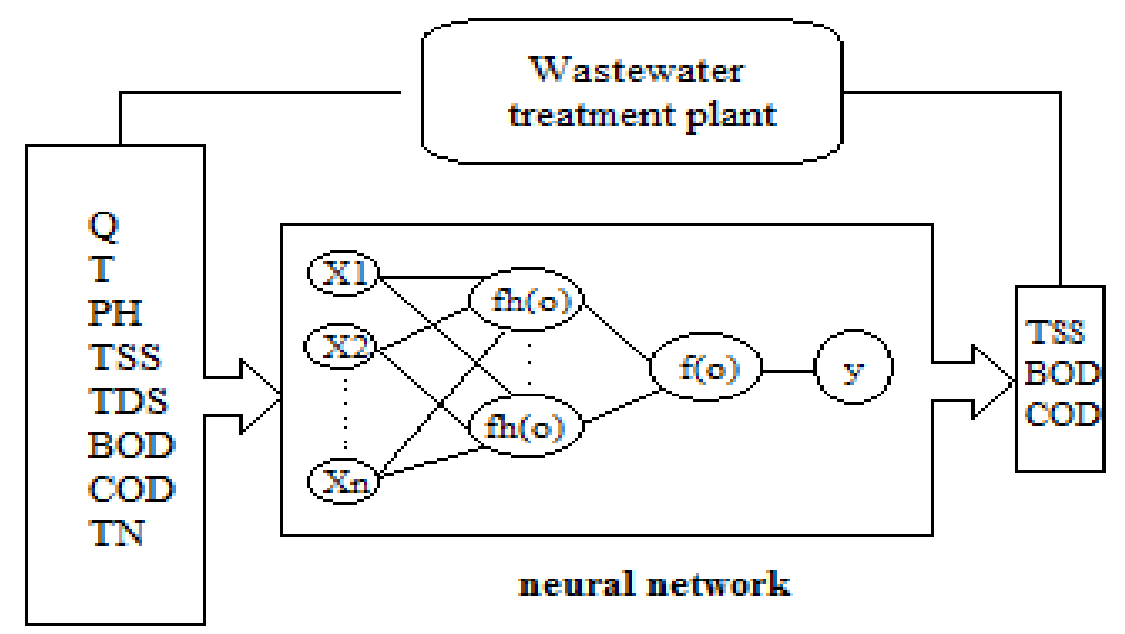

Figure 2. The architecture model of the neural network model. 
Statistical indicators were used during results analysis to express the error rate and comparison between the simulated parameters, including correlation coefficient, mean square error and root mean square error. Based on quantitative and qualitative data of incoming wastewater, effluent, process conditions, meteorological information, and, finally, the effluent, the factors affecting the performance of the treatment plant were determined. Next step was prediction of the concentrations of parameters in the effluent based on the determined factors and the neural network model. To achieve higher accuracy in refinery modelling, a genetic algorithm was used to optimize the neural network. Finally, the concentration of each of the three parameters in the effluent was predicted and the statistical criteria of correlation coefficient $R$, Mean relative root mean squared prediction error (rRMSPE), and the mean absolute percentage of relative error (rMAPE) were measured with their actual amount and thus the model was evaluated [17].

\section{Results}

In this study, the genetic algorithm sought the optimal answer for 450 generations and evaluated 150 possible answers in the search space in each generation. For the BOD parameter, the results of 5 model runs are summarized in the effluent. The maximum and minimum values of the correlation coefficient of the results obtained from the model were equal to $0.93,0.86$, and 1.08 , respectively, the average of which was calculated to be a suitable number due to the semi-modern nature of the treatment plant (Table 1).

Table 1. Predictive results of TSS, BOD and COD parameters of wastewater treatment plan.

\begin{tabular}{ccc}
\hline Parameter & $\mathbf{R}$ & $\mathbf{M S E}$ \\
\hline BOD & 0.89 & 2.3 \\
COD & 0.82 & 34.2 \\
TSS & 0.83 & 2.07 \\
\hline
\end{tabular}

Examination of the number of selected neurons in the first and second hidden layers showed that in $16 \%$ of cases, the network had two hidden layers with the average number of neurons in the first layer being 16 and in the second layer 11. In the remaining $84 \%$, the network had only one hidden layer, with an average of 14 neurons. On average, the best network structure had two hidden layers with an average number of neurons in the first layer of 15 and 2 in the second layer. Also, the network had only one hidden layer with 11 neurons at the maximum value of the correlation coefficient (R). GA-ANN model with a maximum correlation coefficient of 0.93 and rRMSPE and rMAPE error rates of $10 \%$ and $7 \%$ has been an efficient model in predicting the concentration of the TBOD parameter and has provided accurate results. This means that it can be used in modelling treatment plants. Due to biological treatment, parameters affecting the growth and activity of microorganisms such as input TCODin/TBODin ratio, dissolved oxygen content, aeration lagoon temperature and input TBOD load were also prioritized in the model predictions. Based on the results obtained from the optimized artificial network model, the factors affecting the performance of the mentioned treatment were determined about the TBOD parameter. In Table 2 A summary of the results is seen along with the weight of each parameter.

Table 2. A summary of the effective factors in predicting the TBOD parameter of effluent along with their related weights.

\begin{tabular}{cc}
\hline Important parameters & Feature weight in predicting TBOD concentrations \\
\hline $\mathrm{Q}$ & 0.8 \\
$\mathrm{DO}$ & 0.88 \\
Input pollution load TBOD & 0.89 \\
Aerator Num & 0.66 \\
$\mathrm{TL}_{\mathrm{L}}$ & 0.85 \\
$\mathrm{~T}_{\mathrm{AIR}}$ & 0.73 \\
\hline
\end{tabular}


In the above table, two parameters (discharge and pollution load) are among the input parameters that play an important role in predicting the quality of wastewater. Based on the available data, it was observed that the flow rate is higher than the designed flow rate in most cases, and one of the available solutions could be to reduce the input flow rate. Among process parameters, dissolved oxygen (DO) and lagoon temperature had high priority in predicting effluent TBOD. In general, the type of aeration system and its rate can be directly on the dissolved oxygen. Lagoon temperature as well as TSS precipitation rate are effective. One of the best ways to improve the performance of the treatment plant is a use of a deep aeration system instead of surface aeration effectively increases the concentration of dissolved oxygen, increases the temperature of the aeration lagoon content, and creates the desired mixing.. Since aeration lagoon system is situated on the open, it is practically and directly impossible to take effective action to control the effect of air temperature ( $\left.\mathrm{T}_{\mathrm{AIR}}\right)$ on the treatment system. However, by using deep aerators instead of surface aerators, the effect of air temperature on the temperature of the aeration lagoon content can be reduced. Because the air is more in contact with the surface of the aeration lagoon, the highest heat energy loss occurs in surface aerators.According to the test results of this study, the most important parameter in predicting the quality of wastewater was the amount of inflow. Based on the statistics and information of the project, the inlet flow rate to the treatment plant in the following years can be obtained with a good approximation in the mentioned plan, the rate of increase of TBOD and TSS input concentration for every 10 years is equal to $5 \%$. Therefore, considering this increasing rate, the concentration of TBOD and TSS of wastewater entering the treatment plant each year in the period 2021-2025 is estimated to be 1.005. In order to predict the quality of the effluent, assuming no corrective action to improve the performance of the treatment plant, the model was implemented in two modes. In the first case scenario, the network structure and the weight of the features were considered following the case where the model had the maximum correlation coefficient. In the second case, the average number of neurons in each layer and the mean weight of the features in 15 times of model execution were considered for the structure and weight of the features. In the first case, the implementation of the model about the TBOD parameter provided better results, which are summarized in Figure 3.

These concentrations are much higher than the standard TBOD parameter in the effluent. Therefore, it is necessary to implement appropriate strategies to improve the quality of the effluent as soon as possible and ensure the efficiency of the solutions and the real improvement of the quality of the effluent during different stages according to the model predictions.

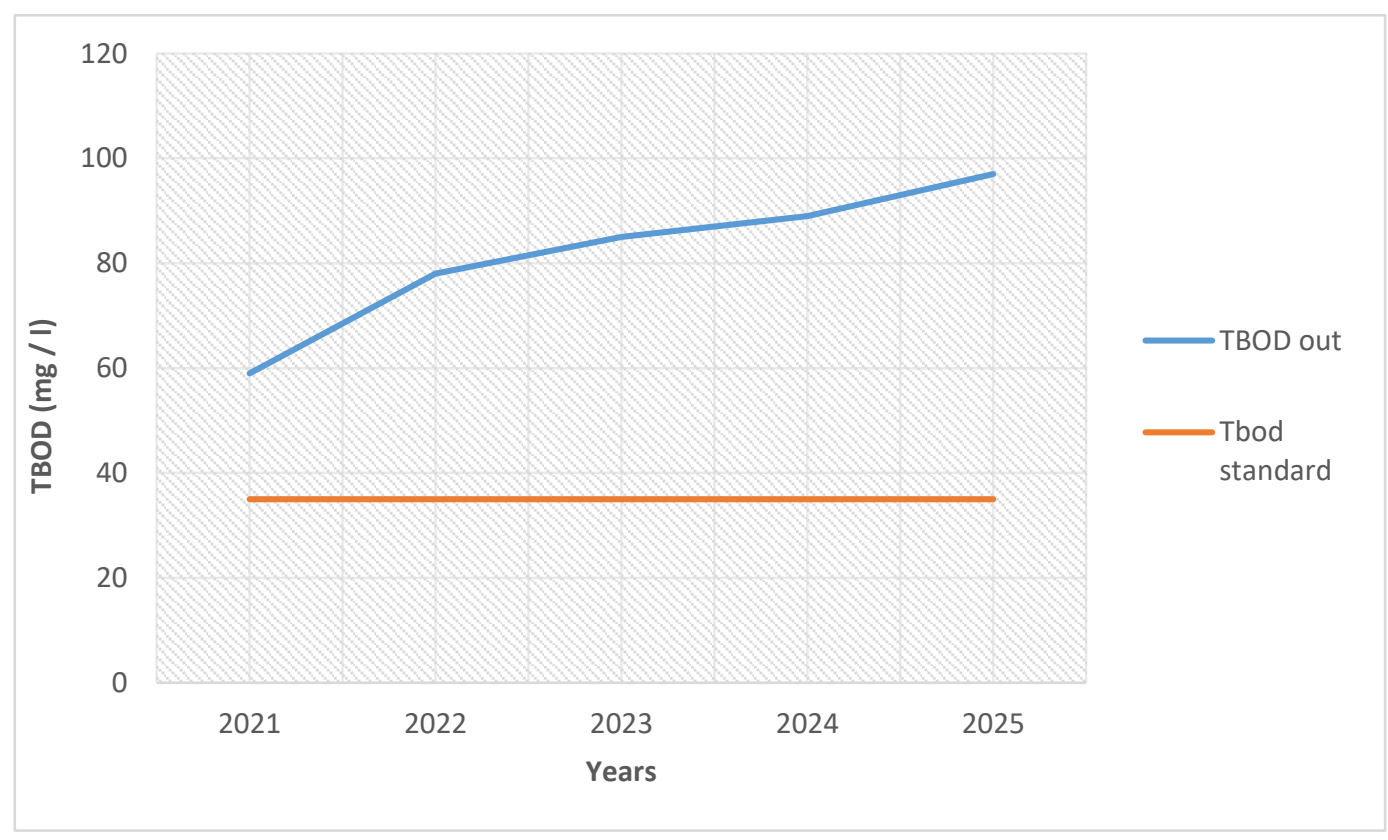

Figure 3. Predicting the average annual concentration of TBOD parameter in the effluent of the treatment plant (mg/l). 


\section{Conclusion}

The present study was conducted to evaluate the performance of Mashhad wastewater treatment plant and to estimate the quality factors of incoming wastewater and effluent with the aim of developing and evaluating the efficiency of the optimized artificial intelligence network model. In general, based on the results of the conducted study, the results were as follows. In semi-mechanical treatment plants various factors affect the performance of the system. In general, these factors can be divided into three groups: quantitative and qualitative parameters of incoming wastewater, process parameters and climate parameters. Based on the obtained results, the most important factors affecting the performance of Mashhad treatment plant were inlet flow rate, TCODin/TBODin ratio, temperature and load of organic matter in the incoming wastewater, and among the process factors the amount of dissolved oxygen, temperature and $\mathrm{pH}$ in lagoon content and several active aerators. Climate factors affecting the performance were air temperature and number of sunny hours. The neural network model was optimized by a genetic search algorithm with complete search and the results were obtained in the maximum correlation coefficient for the TBOD parameter equal to 0.89 and the corresponding rRMSPE and rMAPE for the qualitative parameter equal to $10 \%$ and $7 \%$, respectively. The neural network model singled out important parameters in predicting the concentration of TBOD parameter in the effluent - discharge rate and a load of organic matter pollution of incoming wastewater, among process factors - dissolved oxygen concentration, lagoon content temperature, and several active aerators and from climatic conditions - air temperature. The inlet discharge of the studied treatment plant in comparison to other inlet characteristics had a higher weight in predicting the concentration of the TBOD parameter of the effluent. Therefore, to improve the performance of the said treatment plant, necessary measures should be taken to reduce and control the inlet flow to different units of the treatment plant.

Author Contributions: S.D. and A.P. conceived and designed the experiments; S.D. and A.P. performed the experiments; B.Đ.. and D.D. analyzed the data; A.P., S.D., B.Đ. and D.D. contributed materials/analysis tools; S.D., A.P., B.Đ. and D.D. wrote the paper.

Conflicts of Interest: The authors declare no conflict of interest.

\section{Abbreviations}

The following abbreviations are used in this manuscript:

BOD5: Biochemical Oxygen Demand in 5 days

COD: Chemical Oxygen Demand

TSS: Total Suspended Solids

TBOD: Total Biochemical Oxygen Demand

TCOD: Total Chemical Oxygen Demand

DO: Dissolved Oxygen

rRMSPE: Mean relative root mean squared prediction error

rMAPE: mean absolute percentage of relative error

\section{References}

1. Vajedi M., Shahhosseini SH. Modeling of Activated Sludge Process Using Sequential Adaptive Neuro-fuzzy Inference System(In Persian), J Wat and waste 2013, 335,pp.121-131.

2. Qasim, S.R. Wastewater Treatment Plants: Planning, Design, and Operation, Chemical Rubber Company (CRC) 1998, pp. 1126.

3. G., Burton, F.L., Stensel, H.D. Wastewater Engineering: Treatment and Reuse. Series: McGraw-Hill Series in civil and environmental Engineering 2004, pp. 1819.

4. Pescod MB. Wastewater Treatment and Use in Agriculture. Italy: Food and Agriculture Organization of the United Nations 1992, pp. 4.

5. Saeedi M, Khalvati F, Ahiliani A. Application of electro-coalescence to reduce COD of the southern Pars gas refinery wastewater (In Persian). J of Wat and Waste 2012, 73, pp.40-48.

6. Qasim SR. Wastewater Treatment Plants: Planning, Design Operation. 2nd ed.New York: McGraw Hill1991. 
7. Arceivala, S.J. Water pollution Control. New York: Mc Graw-Hill 1989, 2, pp.189-193.

8. Raha D. Exploring Artificial Neural Networks Modeling for a Biological Nutrient Removal (BNR) Sewage Treatment Plant (STP) to Forecast Effluent Suspended Solids. Indian Institute of Chem Engin 2010, 49(3), pp.205-220.

9. Eckenfelder WW. Industrial water pollution control. New York: Mc Graw - Hill. 2000; 2:189-193.

10. Zare Abiane H, Bayat Varkeshi M, Bayat Varkeshi J. Evaluation of Ekbatan wastewater treatment plant using artificial neural network (In Persian). J of Envirology 2013, 38, pp. 85-98.

11. Oliveira-Esquerre, K.P., Seborg, D.E., Bruns, R.E., and Mori, M. Application Of Steady-State And Dynamic Modeling For The Prediction Of The BOD Of An Aerated Lagoon At A Pulp And Paper Mill: Part I. Linear Approaches, Chemical Engineering Journal 2004,104,pp.73-81.

12. Cao G., Li M., Mo C. Prediction Of The Anaerobic Systems Based On Neural Network With Multipopulation Parallel Genetic Algorithm, Second International Symposium on Intelligent Information Technology Application,2008, pp. 947-951.

13. Abu Qdais H., Bani Hani K., and Shatnawi N. Modeling and Optimization of Biogas Production from A Wastewater Digester Using Artificial Neural Network and Genetic Algorithm, Journal: Resources, Conservation and Recycling 2010, 54, pp. 359-363.

14. Fang, F., Ni, B.J., Xie, W.M., Sheng G.P., Liu S.G., Tong Z.H., Yu H.Q. An Integrated Dynamic Model for Simulating a Full-Scale Municipal Wastewater Treatment Plant Under Fluctuating Conditions, Chemical Engineering Journal, 2010,160, pp. 522-529.

15. Gueguim Kana, E.B., Oloke, J.K., Lateef, A., Adesiyan, M.O. Modeling and Optimization of Biogas Production On Saw Dust and Other Co-Substrates Using Artificial Neural Network And Genetic Algorithm, Renewable Energy 2010, 46, pp. 276-281.

16. Piuleac, C. G., Curteanu, S., Rodrigo, M.A., Sáez, C., and Fernández, F.J. Optimization Methodology Based On Neural Networks and Genetic Algorithms Applied to Electro-Coagulation Processes, Central European Journal of Chemistry 2010, 11(7),pp. 1213-1224.

17. Armstrong, J. S., Collopy, F. Error Measure for Generalizing About Forecasting Methods: Empirical Comparisons, International Journal of Forecasting 1992, 8, pp. 69-80. 